\title{
SISTEM PAKAR MENGIDENTIFIKASI PENANGGULANGAN PENYAKIT PADA GIGI DAN MULUT
}

\author{
Christian Tonyjanto \\ Prodi Sistem Informasi, Fakultas IKST, Universitas Dhyana Pura, Badung - Bali \\ christian_tonyjanto@hotmail.com
}

\begin{abstract}
:
Expert systems are knowledge-based systems, where the knowledge is gained from the and run the expert system we require human expertise. One of the implementations in a wide range of experts in their respective fields. The program is an expert system that applies a program like the experts are useful, because the computer will not forget, will not lose temper, will not die, will -not likely do a calculation error and soon.

However, we will not forget the human factor, because to make the necessary expert systems or the identification process of diagnosing the symptoms. In writing this essay will be designed an expert system that can later be used to diagnose diseases contained in the teeth and mouth disease.This expert system is a reference for people to be able to know and deal with it quickly. Keywords : Expert System, Artificial Intelligent.
\end{abstract}

\begin{abstract}
ABSTRAK
Sistem pakar merupakan sistem yang berbasis ilmu pengetahuan, dimana ilmu pengetahuan yang diperlukan untuk menjalankan sistem pakar yang berasal dari keahlian manusia. Sistem pakar dapat diimplementasikan ke dalam berbagai macam bidang ilmu. Program sistem pakar merupakan program yang berperilaku seperti ahli atau pakar dalam sebuah bidang ilmu, dikemas dalam bentuk aplikasi komputer yang tidak akan salah menangkap atau mengolah informasi, tidak melakukan kesalahan perhitungan dan sebagainya.

Faktor manusia memegang peranan penting dalam perancangan sistem pakar, karena untuk merancang sistem pakar diperlukan proses pendiagnosaan atau pengidentifikasian gejala penyakit. Dalam penelitian ini, akan dirancang sebuah sistem pakar yang akan digunakan untuk mendiagnosa penyakit pada gigi dan mulut. Sistem pakar ini merupakan referensi bagi para penderita, dokter dan rumah sakit untuk dapat mengetahui dan menanganinya secara cepat.
\end{abstract}

Kata Kunci : Sistem Pakar, Kecerdasan Buatan.

\section{PENDAHULUAN}

Semakin banyak penyakit, banyak juga cara penanganannya. Dan biasanya penderita seringkali mengambil jalan yang cepat tanpa memikirkan akibat yang harus terjadi setelah masa pengobatan.

Karena cukup banyak varian penyakit yang dapat dan tidak dapat ditangani secara mu-dah. Untuk itu diambil permasalahan pena-nganan penyakit mulut dan gigi. Yang sering menjadi permasalahan dalam hal bertatap muka antara pasien dengan yang dokter yang menangani.

Dengan semakin majunya ilmu pengetahuan dan teknologi terutama di bidang komputer, saat ini sudah banyak sekali perangkat lunak (software) dan perangkat keras (hardware) yang menunjang kemajuan ilmu penge-tahuan dan teknologi tersebut. Dengan perkembangan tersebut maka dirancang suatu perangkat lunak yaitu sebuah sistem pakar yang dapat membantu penderita dalam mendiagnosa (mendeteksi) dan mengetahui jenisjenis penyakit beserta penanggulangan-nya secara sementara yang terdapat didalam mulut dan gigi dengan pengetahuan dan hasil yang sejajar dengan seorang ahli atau pakar, hanya dengan mengetahui gejala-gejala yang dirasakannya.

\section{TINJAUAN PUSTAKA}

Sistem Pakar merupakan salah satu bagian dari sub bidang kecerdasan tiruan. Pembatasan terhadap topik permasalahan ini sangat diperlukan untuk memperjelas mengenai masalah yang akan dibicarakan sesuai dalam penelitian ini. 
Pembahasan mulut dan gigi sangatlah luas dan mendalam. Penulis membatasi ruang lingkup penulisan skripsi ini hanya pada pembahasan penyakit pada mulut dan gigi dan bagaimana memindahkan pengetahuan seorang ahli kedalam program sistem pakar berdisainkan web.

Penyakit pada mulut dan gigi terbagi da-lam pembahasan mengenai gejala - gejala serta solusi pengobatannya. Pendiagnosaan jenis penyakit mulut dan gigi ini ada 72 jenis penyakit yang diantaranya pada mulut 66 jenis penyakit, pada gigi 6 jenis penyakit, yang sewaktu-waktu dapat berubah sesuai dengan perkembangan dan kebutuhan sistem.

Di dalam sistem pakar ini teknik inferensi yang digunakan adalah pelacakan dan pencarian. Teknik pelacakan yang digunakan adalah teknik pelacakan ke depan (Forward Chaining). perangkat lunak (software) dan perangkat keras (hardware).

Dalam bidang komputer kecerdasan tiruan adalah suatu cara agar komputer dapat menirukan pola pikir manusia yang nantinya dapat disejajarkan sebagai alat bantu manusia dalam mempermudah memecahkan masalah. Beberapa aplikasi yang meliputi kecerdasan tiruan adalah seperti berikut :

a.Sistem pakar (expert system). Disini komputer digunakan sebagai sarana untuk menyimpan pengetahuan sistem pakar, dengan demikian komputer akan memiliki keahlian untuk menyelesaikan permasalahan dengan meniru keahlian yang dimiliki oleh pakar yang bersangkutan.

\section{Pohon Keputusan}

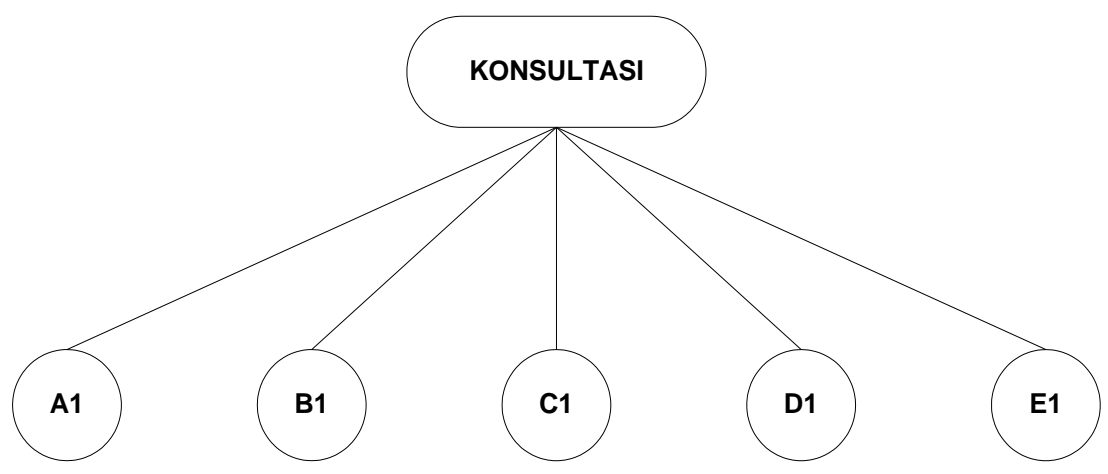

Gambar 1. Pohon Keputusan Konsultasi Permasalahan

Keterangan :

A1:Permasalahan yang dihadapi terletak pada Mukosa Pipi. B1:Permasalahan yang dihadapi dengan tidak hilang digosok. C1:Permasalahan yang dihadapi bau mulut pada penderita. D1:Permasalahan yang terletak pada mukosa bibir. E1:permasalahan yang dihadapi dengan gejala yang lain.

Sedangkan untuk pencarian keputusan dari setiap permasalahan digunakan metode pen- carian Best First Search yaitu pencarian yang menggabungkan dua metode pencarian yang ada, yaitu metode Breadth First Search dan Depth First Search.

\section{Kecerdasan Tiruan}

Kecerdasan tiruan atau Artifical Intelligence merupakan salah satu bagian dari ilmu komputer yang tujuan untuk membuat
b.Robotika dan sistem sensor. Pengenalan ucapan (speech recognition). Melalui pengenalan ucapan diharapkan manusia dapat berkomunikasi dengan komputer menggu-nakan suara. c. Pengolahan bahasa alami (natural language processing). Dengan pengolahan bahasa alami ini diharapkan pemakai (user) dapat berkomunikasi dengan komputer menggunakan bahasa sehari-hari. d. Computer vision mencoba untuk dapat menginterpretasikan gambar atau objek-objek tampak melalui komputer.

\section{Sistem Pakar}

Sistem pakar adalah suatu program yang mengkomputerisasikan laporan dengan mencoba menirukan proses pemikiran dan pengetahuan dari pakar atau ahli dalam 
memecahkan tipe tertentu dari suatu masalah (Turban dan Efrain, 1992).

Berdasarkan kegunaannya sistem pakar dapat dikembangkan menjadi empat macam, yaitu :

1) Diagnosa Sebelum menentukan hasil atau kesimpulan biasanya melakukan diagnosa yang berupaya pertanyaan - pertanyaan, sistem pakar ini menggunakan pohon keputusan sebagai representasi pengetahuan. 2) Kontrol. Sistem pakar ini biasanya digunakan pada industri - industri yang berteknologi canggih. Karena sistem pakar ini digunakan untuk mengontrol aktifitas dengan menggunakan waktu yang seefektif mungkin. 3) Interpretasi. Berguna untuk menganalisa data yang tidak lengkap, tidak teratur dengan data yang kontradiktif. 4) Perencanaan. Dengan memakai sistem pakar ini akan menghemat waktu dan biasanya karena dalam pembuatan model sudah tidak diperlukan lagi.

\section{Metode pelacakan atau penelusuran}

Metode pelacakan atau penelusuran adalah penyediaan sebuah jalan atau path dari beberapa pendekatan tidak langsung yang tersedia untuk memecahkan dan menyelesaikan persoalan. Metode pelacakan atau penelusuran dapat dibedakan menjadi tiga cara, yaitu :

\section{Depth First Search}

Depth first search adalah teknik penelusuran data pada node-node secara vertical dan sudah terdefinisikan, misalnya dari kiri ke kanan.

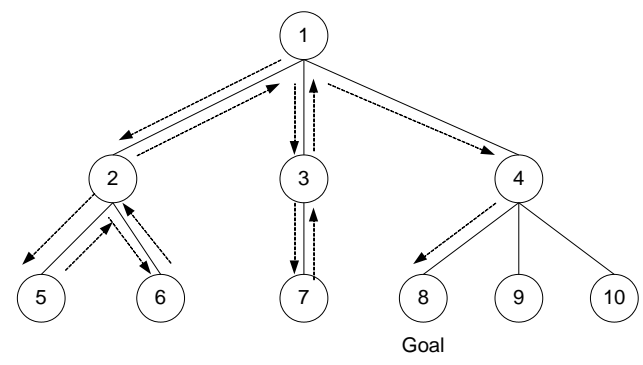

\section{Gambar 2. Penelusuran Data dengan Depth First Search}

\section{Breadth First Search}

Breadth first search adalah teknik penelusuran data pada semua node dalam satu level atau satu tingkatan sebelum ke level atau tingkatan di bawahnya.

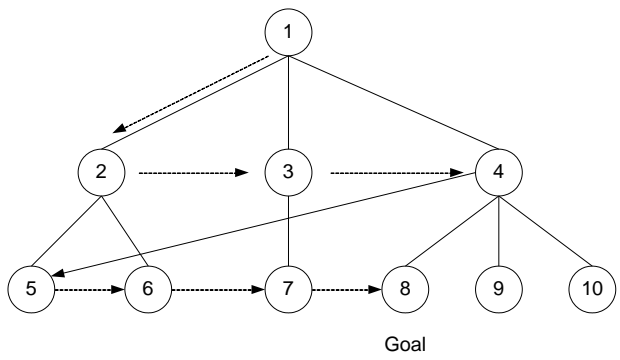

\section{Gambar 3. Penelusuran Data dengan Breadth First Search}

\section{Best First Search}

Best first search adalah penelusuran yang menggunakan pengetahuan akan suatu masalah untuk melakukan panduan pencarian kearah node tempat dimana solusi berada. Pencarian jenis ini dikenal juga sebagai heuristic.

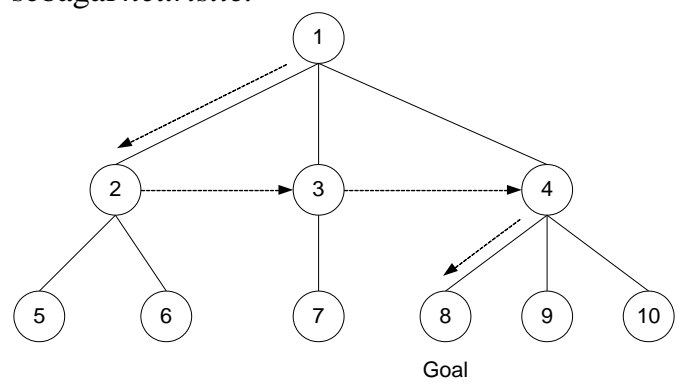

\section{Gambar 4. Penelusuran Data dengan} Best First Search

\section{Mesin Inferensi (Inference Engine)}

Bagian yang mengandung mekanisme fungsi berpikir dan pola-pola penalaran sistem yang digunakan seorang pakar. Mekanisme ini akan menganalisa sesuatu masalah tertentu selanjutnya mencari kesimpulan yang terbaik serta memilih pengetahuan yang relevan dalam rang- ka mencapai kesimpulan sesuai dengan kondisi yang ada. Ada dua cara dalam melakukan inferensi, yaitu :

\section{Metode pelacakan ke depan (Forward Chaining )}

Metode ini melakukan pelacakan mulai dari sekumpulan fakta, lalu melakukan pengecekan terhadap bagian dari fakta sampai menemukan kecocokan. Pelacakan ini dilakukan sampai di dapat suatu kesimpulan. Metode ini dikenal dengan Data Driven. 


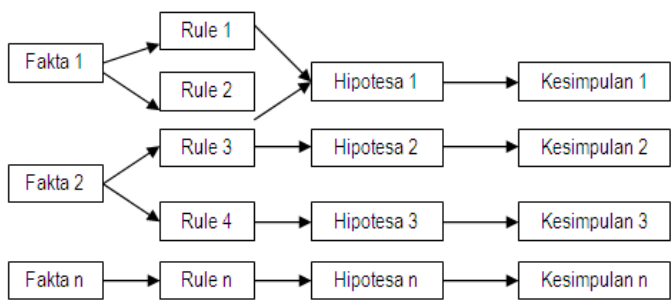

Gambar 5. Forward Chaining

\section{Pelacakan ke belakang ( Backward Chaining )}

Metode ini melakukan pelacakan balik mulai dari suatu kesimpulan atau tujuan (goal), kemudian ke aturan-aturan sampai akhirnya di- peroleh fakta - fakta. Dalam kasus ini tujuannya sudah ditentukan terlebih dahulu dan sebuah sistem pakar mencoba menentukan kondisi-kondisi apa saja yang dibutuhkan untuk mencapai kesimpulan atau tujuan tersebut.

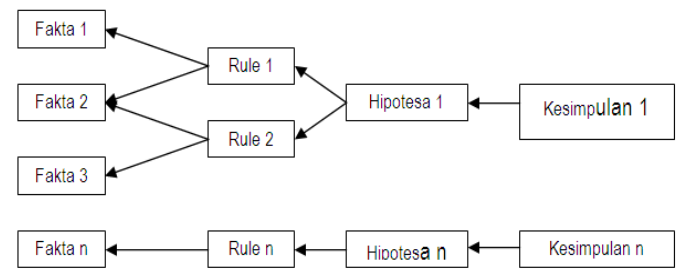

\section{Gambar 6. Backward Chaining}

\section{Bahasa Pemrograman}

\section{HTML (Hyper Text Markup Language)}

HTML adalah suatu bahasa markup (penan- daan) terhadap sebuah dokumen teks. Tanda tersebut digunakan untuk menentukan format atau style dari teks yang ditandai. Simbol mark- up yang digunakan oleh HTML ditandai dengan tanda lebih kecil "<" (tag awal) dan tanda lebih besar ">" (tag akhir) dan disebut dengan tag. HTML merupakan suatu format data yang digunakan untuk membuat dokumen hyper text yang dibaca dari suatu platform komputer lain- nya tanpa perlu melakukan suatu perubahan. Dokumen HTML adalah suatu dokumen teks biasa, sehingga padasegala jenis konfigurasi dokumen tersebut dapat dibaca.

\section{PHP (Personal Home Page)}

Bahasa PHP memberikan banyak kemudahan dalam penggunaannya. PHP mempunyai kemampuan pemrograman yang bagus. Seperti keluwesan dalam penggunaan dan konversi tipe data. Selain itu PHP juga memiliki keunggulan dalam hal pengolahan database. Untuk mem -buat suatu aplikasi yang besar yang memerlukan kecepatan pengaksesan dan kekuatan data di-perlukan suatu sistem database yang baik. Sistem yang didukung oleh PHP adalah :Oracle, Sybase $M S Q L$, Soid Generic ODBC Postgres SQL.

\section{MySQL}

MySQL adalah salah satu jenis database server yang sangat terkenal. Kepopulerannya disebabkan MySQL menggunakan $S Q L$, karena bahasa dasar untuk mengakses databasenya. Selain itu, program ini bersifat free (tidak perlu membayar untuk menggunakannya) pada berbagai platform. Pada MySQL, sebuah database mengandung satu atau sejumlah tabel. Tabel terdiri atas sejumlah baris dan setiap baris mengandung satu atau beberapa kolom.

\section{HASIL DAN PEMBAHASAN}

Sistem Pakar ini dikemas dalam aplikasi teknologi dengan berbasis web. Teknologi yang dipakai web ini, secara umum dibedakan menjadi dua, yaitu server side dan client side. Pada server side, proses akan dilakukan di web server, sedangkan client (web browser) hanya akan menerima hasilnya dalam bentuk HTML. Contoh server side adalah ASP, JSP, PHP dan CGI/Perl. Pada client side, proses akan di-lakukan di web browser. Biasanya client side digunakan untuk hal-hal yang membutuhkan banyak interaksi user dan menggunakan jenis informasi yang pasti dan seragam.

Dalam menjalankan program yang dibuat disini, maka diperlukan sebuah web server yang berfungsi sebagai tempat penyimpanan program. Web server yang digunakan dapat berupa Apache Web Server, IIS (Internet Information Service). Pada aplikasi ini menggunakan Apache Web Server dan MySQL sebagai database server.

Program sistem pakar ini telah diujicobakan pada dua perangkat komputer dengan spesifi-kasi software dan hardware dan juga telah dilakukan pada jaringan,sebagai berikut :

(1)Komputer Server :

Prosessor:Intel Pentium 4 2.4B Ghz;

Memory: 1024 MB PC2700 (512 mb x2); Hard disk System: Seagate 40 GB 7200 Rpm; Data 1: Maxtor 40 
GB 5400 Rpm Data 2: Seagate120GB SATA 150; Soundcard: Creative Live! DE 5.1; Network Card: Marvell 10/100/1000 mbps; Sistem Operasi: Microsoft Windows XP Professional SP;

(2) Komputer Client dua unit: Komputer Client 1:

Prosessor: Intel Pentium 4 1.5 Ghz; Memory: 384 MB PC800; Harddisk: Seagate 60 GB 7200 Rpm; Soundcard : Creative Vibra 128; Network Card: Dlink 10/100 mbps; Sistem operasi: Microsoft Windows XP Professional SP1;

Komputer Client 2:

Prosessor: Intel Pentium 4 1.6 Ghz; Memory: 512 MB PC133; Hard disk: Maxtor 80 GB 7200 Rpm; Soundcard: Realtek AC'97

Onboard; Network Card: SMC 10/100 mbps; Sistem operasi : Microsoft Windows XP Professional SP2; Perangkat jaringan yang di-gunakan: Router Linksys 4 port 10/100 with WLAN; Cable Modem Com21;UTP Cable cat 5E.

Dari proses uji coba sistem pakar dengan menggunakan beberapa jenis komputer yang dihubungkan ke dalam jaringan, terlihat bahwa hasilnya tidak jauh berbeda de-ngan spesifikasi komputer yang dipakai untuk membuat sistem pakar.

Hal ini dilakukan untuk mencoba perangkat lunak yang dibuat ini bisa dilakukan di dalam jaringan yang dapat digunakan pada sebuah rumah sakit, agar pada saat implementasi nantinya sudah dapat dipakai langsung tanpa harus menaruh semuanya didalam semua komputer.

Jadi dapat disimpulkan untuk menghasilkan kinerja yang bagus, disarankan untuk memakai program sistem pakar ini minimal komputer yang dipakai adalah minimal pentium III, dengan memory minimal $256 \mathrm{MB}$ dan sistem operasi minimal windows 98 , dan optimal menggunakan internet explorer versi 5.5 keatas.
Diagram alir yang ada dalam sistem pakar akan digambarkan pada gambar berikut:

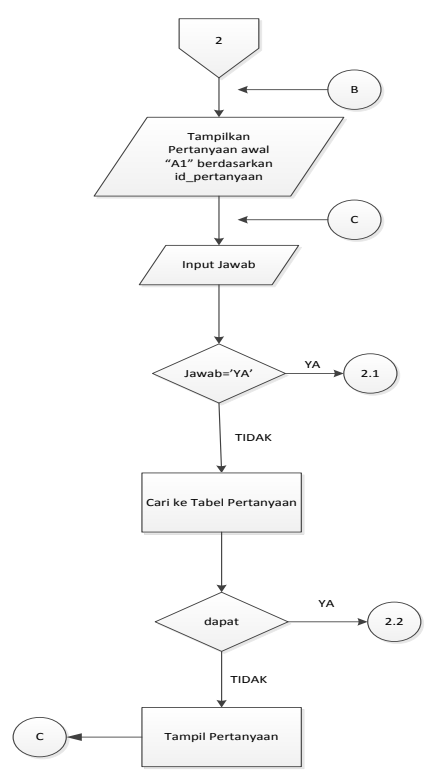

Gambar 7. Diagram Alir Sistem Pakar 1

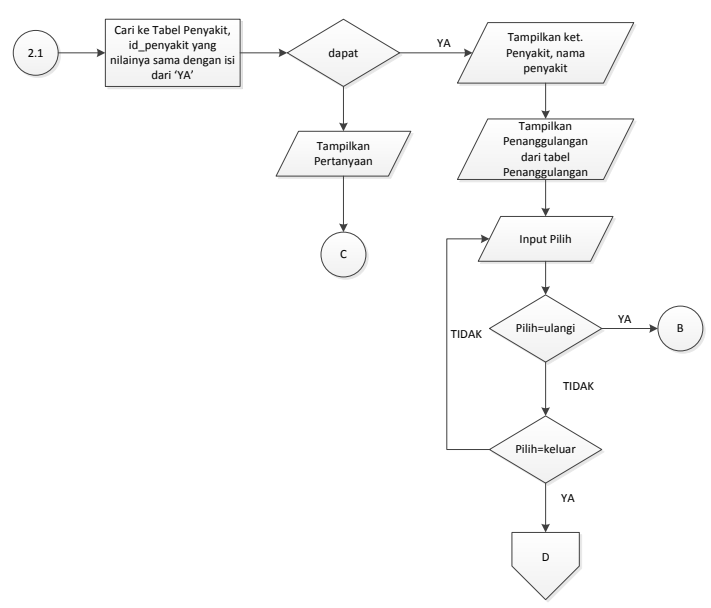

Gambar 8. Diagram Alir Sistem pakar 


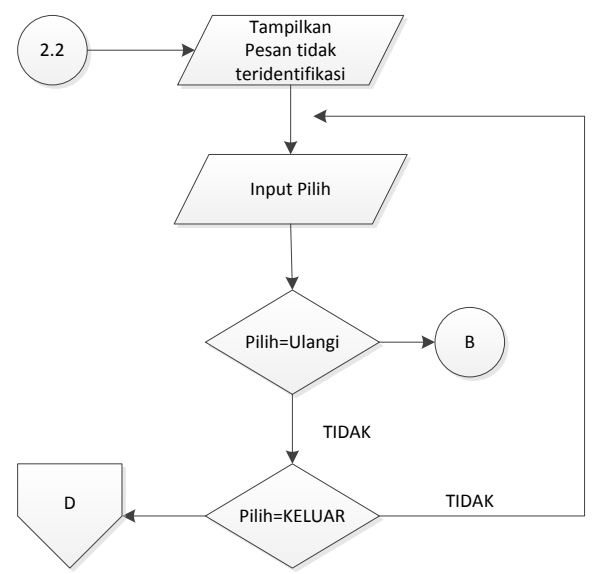

Gambar 9. Diagram Alir Sistem Pakar 3

\section{SIMPULAN}

Sistem yang dibuat ini, sudah sangat mudah untuk dapat digunakan dan juga dapat membantu banyak pihak yang masih awam menggunakan aplikasi berbasis komputer. Sistem pakar ini dibuat berda-sarkan hasil penelitian beberapa masyarakat dan seorang dokter, serta ditambah dari referensi buku-buku pendukung yang dikem-bangkan ke dalam program yang berbentuk halaman web. Metode pencarian yang dipakai adalah Best First search agar lebih efi-sien dalam menyelesaikan masalah.

\section{DAFTAR PUSTAKA}

[1] Gayford J.J \& Haskell R, Penyakit Mulut (Clinical Oral Medicine), Penerbit Buku Kedokteran EGC, Jakarta, 1990

[2] Langlais Robert P.,DDS, MS \& Miller Craig S., DMD, MS, Atlas Berwarna Kelainan Rongga Mulut yang Lazim (Color Atlas of Common Oral Diseases), Penerbit Hipokrates, Jakarta, 1994

[3] Kadir Abdul, Dasar Pemrograman Web Dinamis Menggunakan PHP, Andi Offset, Yogyakarta, 2003

[4] Kusumadewi Sri, Artificial Intelligence ( Teknik dan Aplikasinya ), Graha Ilmu, Yogyakarta, 2003

[5] Russel Stuart, Norvig Peter, Artificial Intelligence A Modern Approach, Second Edition, Prentice-Hall, New Jersey, 2003
[6] Suparman, Mengenal Artificial Intelligence, Andi Offset, Yogyakarta, 1991

[7] Sutarman S.Kom, Membangun Aplikasi Web dengan PHP dan MYSQL, Graha Ilmu, Yogyakarta, 2003 